\title{
Molecular mechanisms by which hormones and cytokines regulate cell junction dynamics in the testis
}

\author{
Wing-Yee Lui and Will M Lee \\ School of Biological Sciences, University of Hong Kong, Pokfulam, Hong Kong, People's Republic of China \\ (Correspondence should be addressed to W M Lee; Email: hrszlwm @hku.hk)
}

\begin{abstract}
Hormones and cytokines are known to regulate cellular functions in all tissues including testis. These two groups of biomolecules exert a broad spectrum of effects on various aspects of spermatogenesis. Among them, one of the regulatory effects on spermatogenesis is to modulate cell junction restructuring between Sertoli cells and between Sertoli and germ cells in the seminiferous epithelium. The restructuring of cell junctions is crucial to enable the migration of germ cells along the seminiferous epithelium from the basement membrane towards the tubular lumen, and at the same time for their attachment to Sertoli cells for support. This review will summarize the recent findings that focus on the role of hormones (FSH and testosterone) and cytokines (transforming growth factor- $\beta$ s and tumor necrosis factor- $\alpha$ ) on cell junction restructuring in the testis and the molecular mechanisms.
\end{abstract}

Journal of Molecular Endocrinology (2009) 43, 43-51

\section{Introduction}

Spermatogenesis is a process by which spermatogonia (diploid) undergo a series of events, including mitotic and meiotic divisions and morphological differentiation, to become haploid spermatozoa. During spermatogenesis, intricate interactions between Sertoli cells and between Sertoli and germ cells are important for germ cell differentiation and these can be achieved via the precise organization of different types of cell junctions (for review, see Cheng \& Mruk 2002). For instance, neighboring Sertoli cells closely associate with each other to form the blood-testis barrier (BTB) that is constituted by inter-Sertoli tight junctions (TJ) and basal ectoplasmic specializations (ES, an atypical adherens junction (AJ) type). The BTB is important for several reasons. First, it creates a microenvironment for germ cell development and confers apical-basal polarity. Secondly, it segregates meiotic germ cells apart from the systemic circulation, thereby protecting them from autoimmune recognition and potential cytotoxic substances. Thirdly, it must open and close at time intervals to allow the passage of preleptotene spermatocytes from basal to adluminal compartment at stages VIII-IX of the spermatogenic cycle. Fourthly, the delivery of drugs or contraceptives must take into account the constraints imposed by the BTB. Besides, germ cells intimately associate and interact with Sertoli cells for structural support via the AJs and gap junctions, and eventually detach from the epithelium into the tubule lumen at spermiation. Therefore, the junctions at the BTB and the Sertoli-germ cell interface are undergoing extensive restructuring (disassembly and reassembly of junctions) to allow the movement of germ cells along the seminiferous epithelium. Worthy of note is the timely opening and closing of junctions at the BTB that are crucial to allow germ cell migration without affecting the integrity of the barrier.

Hormones and cytokines are known biomolecules that regulate a wide spectrum of cellular functions in different tissues such as testes. In this review, we shall highlight the molecular mechanisms by which testosterone, FSH, transforming growth factor- $\beta$ s (TGF- $\beta$ s), and tumor necrosis factor- $\alpha$ (TNF- $\alpha)$ exert their effects in regulating cell junction restructuring pertinent to spermatogenesis. The architecture of cell junctions in the testis has been extensively reviewed elsewhere (Lui \& Lee 2006, Sofikitis et al. 2008, Wong et al. 2008). Readers are strongly encouraged to read those reviews for a more comprehensive view of the topic.

\section{Testosterone}

Testosterone is a male sex hormone secreted by Leydig cells under the control of luteinizing hormone (LH)

DOI: 10.1677/JME-08-0174 Online version via http://www.endocrinology-journals.org 
released from the anterior pituitary. It is essential for the development of male phenotype and sexual behavior among other tissues (Rahman \& Christian 2007). For instance, the differentiation of round spermatids to elongated spermatids at stages VII-VIII requires the action of testosterone (Sun et al. 1990, McLachlan et al. 1994). While testosterone is produced in the interstitial compartment under the influence of $\mathrm{LH}$, the expression of the androgen receptor (AR) in adult testes is stage-specific and is the highest at stages VII-VIII (Bremner et al. 1994, Shan et al. 1997).

Several in vivo models including hormone-suppression, hormone-restoration and hypophysectomy are available for the study of the hormonal regulation of spermatogenesis by testosterone (Huang et al. 1987, Sun et al. 1989, O'Donnell et al. 1994). Extensive studies have been performed in the past two decades using the suppression and restoration models to understand how testosterone affects spermatogenesis. Testosterone has been shown to exert its effect to control the fate of developing germ cells, in particular the round spermatids (Sun et al. 1990, McLachlan et al. 1994). For instance, the suppression of intratesticular testosterone by testosterone and estradiol implant could interrupt the conversion of round spermatids to elongated spermatids between stages VII and VIII, but could be restored to normal upon high-dose testosterone treatment (O'Donnell et al. 1994). Subsequent studies confirmed that the absence of the elongated spermatids in testosterone-suppressed rats was due to the fact that round spermatids were prematurely detached from the epithelium (O'Donnell et al. 1996). These studies suggest that testosterone affects the adhesive function between round spermatids and Sertoli cells, leading to the sloughing of round spermatids from the epithelium.

The detailed mechanism of how testosterone alters the adhesive function has been recently unraveled. Two protein complexes linking between round spermatids and Sertoli cells at the apical ES, the cadherin/ cadherin and $\alpha 6 \beta 1$-integrin/laminin $\gamma 3$ interlocks, are the affected targets in the testosterone-suppression model (Wong et al. 2005, Zhang et al. 2005b). In normal rat testis, actin-linked $\mathrm{N}$-cadherin/ $\beta$-catenin complexes in both Sertoli cell and round spermatid join together to form intact actin-based cadherin/cadherin AJ interlocks at the cell-cell surface, and such interaction is tightly controlled by kinases and phosphatases such as c-src and myotubularin-related protein 2 (Zhang et al. $2005 a$; Fig. 1). For the $\alpha 6 \beta 1$-integrin/laminin $\gamma 3$ interlock, the interaction of peripheral proteins, focal adhesion kinase (FAK) and c-src, with $\beta 1$-integrin on

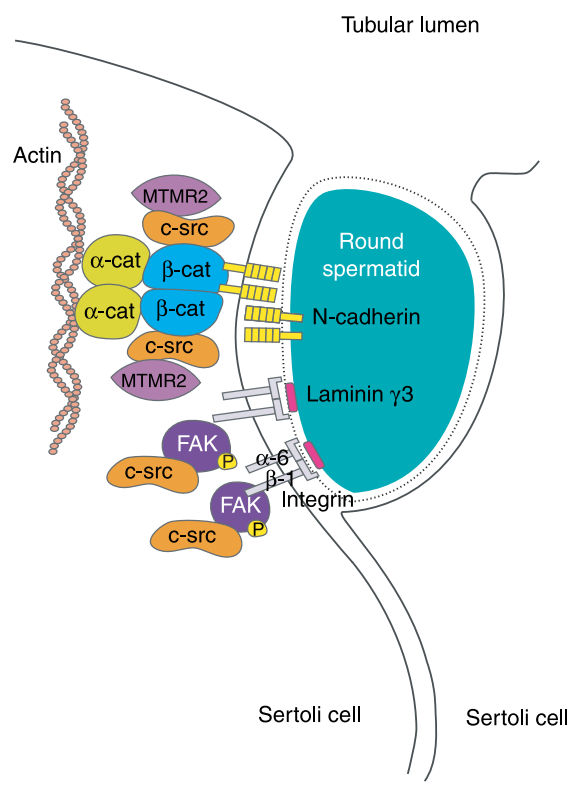

Intact apical ES in the presence of testosterone

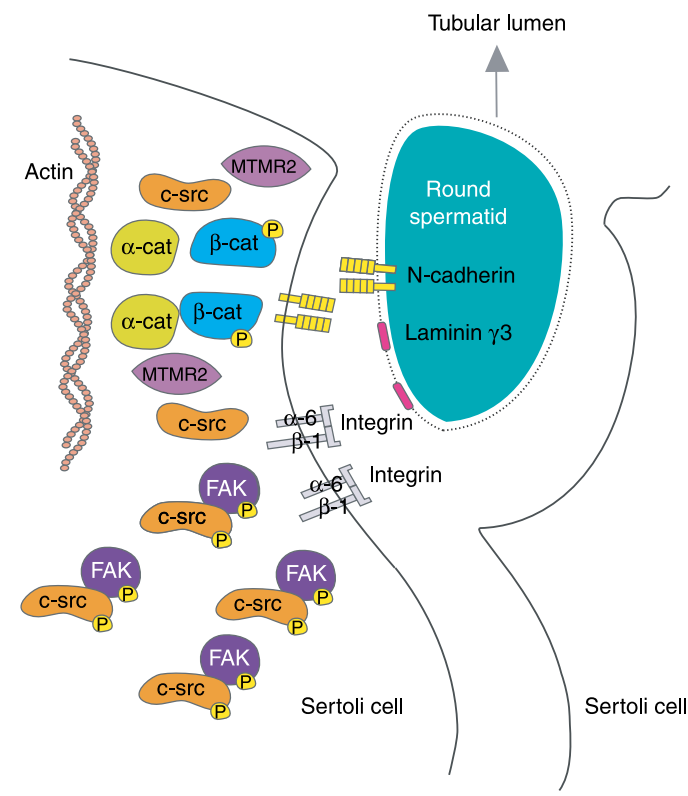

Impaired apical ES in the absence of testosterone

Figure $1 \mathrm{~A}$ schematic drawing illustrates the regulation of apical ES by testosterone. In the presence of testosterone, intact apical ES are established and constituted by cadherin/cadherin (Zhang et al. 2005b) and integrin/laminin interlocks (Wong et al. 2005). Cadherin and integrin are closely associated with their cytoplasmic interacting partners to form stable ES (Wong et al. 2008). In the absence of testosterone, a significant increase in phosphorylation of $\beta$-catenin (Zhang et al. 2005b) and FAK (Wong et al. 2005) are observed. The change of phosphorylated state of the cytoplasmic partners destabilizes the protein interlocks, resulting in the disassembly of the apical ES. $\alpha$-cat, $\alpha$-catenin; $\beta$-cat, $\beta$-catenin; MTMR2, myotubularin-related protein 2; FAK, focal adhesion kinase; ES, ectoplasmic specializations. 
the Sertoli cell side is important to maintain the integrity of the $\alpha 6 \beta 1$-integrin/laminin $\gamma 3$ interlock (Yan \& Cheng 2006).

By the use of the testosterone-suppression model again, it has been found that in the absence of testosterone there are apparent changes in the degree of protein-protein interactions and the levels and phosphorylation states of several ES proteins at the apical ES, which in fact alters the architecture of the ES and leads to the detachment of round spermatids from the epithelium (Wong et al. 2005, Zhang et al. 2005b; Fig. 1). Significant increases in protein levels of c-src, $\beta 1$-integrin as well as FAK and tyrosine phosphorylation of both FAK and $\beta$-catenin were detected in testosterone-depleted testes. Tyrosine phosphorylation of $\beta$-catenin indeed favors the dissociation of the $\mathrm{N}$-cadherin/ $\beta$-catenin complex, thus destabilizing the cadherin/cadherin interlock found at the interface of Sertoli cells and round spermatids (Zhang et al. 2005b). In the absence of testosterone, the increase in the association of c-src with FAK (but not with $\beta 1$-integrin) under the activation of extracellular signal-regulated kinase (ERK) also affects the integrity of the $\alpha 6 \beta 1$ integrin/laminin $\gamma 3$ interlock at the Sertoli cell/ spermatid interface (Wong et al. 2005). Taken collectively, the two major junction interlocks at the apical ES are seriously disrupted in testosterone-suppressed testis and testosterone thus plays a major role to regulate the adhesive function between Sertoli cells and round spermatids via its action on the protein complexes at the apical ES.

Apart from its role to regulate the dynamics of the apical ES and spermiation in the testis, recent studies have demonstrated that testosterone $\left(2 \times 10^{-7} \mathrm{M}\right)$ also controls the bioavailability of several junction proteins at the BTB by accelerated endocytosis (Yan et al. 2008a). Although the concentration of testosterone used in this study was greater than the $K_{\mathrm{d}}$ of AR $\left(2-5 \times 10^{-10} \mathrm{M}\right)$, the results obtained in the study are of physiological significance (Wilson \& French 1976) since this is the testosterone concentration in the testis which is 100 -fold that of the serum. The reason for the presence of a supraphysiological testosterone level (greater than $K_{\mathrm{d}}$ of the AR) in the testis is unknown; perhaps this is reflected by a different regulation of testosterone entry to the cell. In the rat testis, the androgen-binding protein that regulates the bioavailability of testosterone in extracellular fluid is produced by the Sertoli cells and found within the seminiferous tubular compartment. However, Yan et al. have found that the addition of testosterone into the Sertoli cell culture having wellestablished $\mathrm{TJ}$ and $\mathrm{AJ}$ can accelerate the internalization of junction proteins from the cell surface. Junction proteins including occludin, junctional adhesion molecule-A (JAM-A) and N-cadherin were the target proteins being internalized into the clathrin vesicles and subsequently targeted to early endosomes for transcytosis. It was found that testosterone could enhance the recycling of the internalized junction proteins back to the cell surface (Yan et al. 2008a) and such cycling of junction proteins back and forth between cell surfaces is important in controlling the transient opening of the BTB to allow the migration of spermatocytes. It is postulated that the internalization of BTB junction proteins at the apical end of the migrating spermatocytes facilitates cell movement. Once the spermatocytes move along, testosterone enhances recycling of the internalized junction proteins back to the Sertoli cell surface at the basal region of the spermatocytes to reseal the BTB (Yan et al. 2008a).

Earlier studies by Chung \& Cheng (2001) have revealed that testosterone can up-regulate other tight junction components including claudin-11, claudin-1, E-cadherin and $\beta$-catenin at the mRNA levels in the rat testis. Until recently, Kaitu'u-Lino et al. (2007) have demonstrated that testosterone regulates claudin-11 expression and promotes the localization of claudin-11 and occludin at Sertoli-Sertoli cell interfaces. Along this line, studies by Meng et al. (2005) have shown that testosterone positively regulates the expression of claudin-3 in mice, which is believed to be a transient component of newly-formed tight junctions at the BTB. Although knockout of claudin-11 causes male infertility in mice (Gow et al. 1999), there is still little definitive data available on the detailed regulatory mechanism of claudin members in the testis by testosterone. Taken collectively, testosterone is a master regulator in controlling the bio-availability of the tight junction proteins at the BTB via post-translational and transcriptional pathways.

Generation of the AR knockout (ARKO) and Sertoli cell-selective (SC) ARKO mice in fact has provided significant insights towards understanding the role of androgen in spermatogenesis (Yeh et al. 2002, Chang et al. 2004, De Gendt et al. 2004, Holdcraft \& Braun 2004, Denolet et al. 2006). Mice from these knockout models are all infertile. In particular, it was found that spermatogenic arrest occurred at the pachytene stage in ARKO mice and resulted in severe testis atrophy $(80 \%$ smaller than wild-type; Yeh et al. 2002); whereas SC ARKO testes (28\% smaller than wild-type) displayed spermatogenic arrest at the late spermatocytes/spermatid stages (De Gendt et al. 2004, Holdcraft \& Braun 2004). The numbers of round spermatids and elongated spermatids in SC ARKO mice were reduced to $0-3 \%$ respective to the wild-type (De Gendt et al. 2004). The fact that SC ARKO mice present a testicular phenotype similar to that of the testosteronesuppressed rodent model further strengthens the idea that testosterone and its receptor play specific roles in Sertoli-germ cell adhesion in the seminiferous 
epithelium. With the advance of microarray technique, Denolet $e t$ al. have analyzed and compared the gene profiles of wild-type and SC ARKO mice. A spectrum of genes related to junction restructuring, including structural components (claudin and nectin-like molecule-1) and regulatory components (serine-type protease inhibitors), has been found to be differentially expressed in the SC ARKO mice respective to the wildtype (Denolet et al. 2006), which further suggests that testosterone is indeed a key player in modulating junction dynamics in the testis. It is apparent that testosterone is not only involved in round spermatidSertoli cell adhesion at the apical ES, but also functions as a positive regulator to maintain the integrity of the BTB.

\section{FSH and estrogen}

FSH is vital for normal spermatogenesis in the rodents (for reviews, see McLachlan et al. 2002, O'Donnell et al. 2005). For instance, male mice lacking a functional FSH receptor had impaired fertility and defected elongated spermatids and Sertoli cells (Krishnamurthy et al. 2000, Grover et al. 2004). The expression of FSH receptors on Sertoli cells in adult rats is also stage-specific, being the highest at stages IX and X (Kliesch et al. 1992).

Rat models having both intratesticular testosterone and FSH suppression have been used to study the effect of hormonal suppression on spermiation. Mature spermatids are attached to Sertoli cells via the apical ES. During spermiation, the apical ES are likely to be removed, which is subsequently followed by the formation of tubulobulbar complex (TBC) and the detachment of spermatids from the Sertoli cells. It was found that $\mathrm{T}+\mathrm{FSH}$-suppression severely interrupted spermiation in the rats, more significantly than T- or FSH-suppression alone (Saito et al. 2000, Beardsley \& O'Donnell 2003). Immunohistochemistry analyses have shown that the $\beta 1$-integrin remained associated with the elongated spermatids in the T+FSH-suppressed testis after the removal of the apical ES. The association of the $\beta 1$-integrin in mature spermatids was the likely cause of spermiation failure (Beardsley \& O'Donnell 2003, Beardsley et al. 2006). These data suggest that testosterone and FSH act synergistically to support spermiation possibly by mediating the dissociation of the $\beta 1$-integrin in mature spermatids at spermiation. Another in vivo study in hypophysectomized rats has shown that concurrent testosterone plus FSH treatment, but not testosterone alone, is able to restore normal spermiogenesis and that this restoration is associated with the reorganization of F-actin and vinculin at the ES (Muffly et al. 1994). Other than rat models, studies on Djungarian hamsters have also demonstrated that exogenous supply of FSH to short-day photoperiod ( $8 \mathrm{~h}$ light:16 h darkness) hamsters whose gonadotropins are suppressed could restore the localization of junction proteins such as actin and espin at the apical ES, and claudin-11 and zonula occludens-1 (ZO-1) at the basal region of the seminiferous epithelium (Tarulli et al. 2006). Using the same animal model, Tarulli et al. (2008) have recently found that similar to claudin-11, claudin-3, occludin and JAM-A can rapidly be reorganized at the BTB upon FSH replacement. These results strongly suggest that in addition to spermiation, FSH regulates the integrity and functionality of the BTB via reorganization and relocalization of junction proteins.

An in vitro study has confirmed that FSH is important to stimulate the relocation of ES proteins such as epsin and in the presence of FSH, cultured Sertoli cells are capable of forming not only the classical AJs, but also the AJ belts and the testis-specific ES which contains actin and epsin (Sluka et al. 2006). Other than ES proteins, FSH also regulates the tight junction proteins such as coxsackievirus and adenovirus receptor (CAR) and claudin-11 in the testis (Mirza et al. 2007). It has been reported that FSH up-regulates the CAR mRNA in cultured immature rat Sertoli cells. However, in claudin-11 expression, rat and mouse Sertoli cells responded to FSH treatment oppositely. It was found that FSH could partially stimulate claudin- 11 mRNA in cultured rat Sertoli cells, and it inhibited the expression of claudin-11 mRNA in mouse Sertoli cells (Hellani et al. 2000, Kaitu'u-Lino et al. 2007). Despite the fact that the importance of FSH in regulating junction restructuring has been known for a long time, the molecular mechanism explaining how FSH exerts its effect remains enigmatic. Further studies in this area are highly warranted.

Apart from FSH, the effects of estrogen on spermiation have been recently examined (D'Souza et al. 2008). Confocal microscopic studies have confirmed that administration of $17 \beta$-estradiol to rats, which causes a rise in intratesticular $17 \beta$-estradiol and suppression of circulating FSH and intratesticular testosterone could result in the disruption of the TBC in elongated spermatids and spermiation failure. It is believed that $17 \beta$-estradiol affects the Sertoli cell cytoskeleton and Arp2/3 complex which are critical for de novo polymerization of actin during TBC formation (D'Souza et al. 2008).

\section{Molecular mechanism of cytokines on reg- ulating junction restructuring in the testis}

TGF- $\beta$ s and TNF- $\alpha$ are known to regulate multiple physiological functions including germ cell development, Leydig cell steroidogenesis and extracellular matrix (ECM) biosynthesis in the testis (for reviews, see 
Lui et al. 2003a, Siu \& Cheng 2004). In addition, there is accumulating evidence showing that TGF- $\beta$ s (TGF- $\beta 2$ and TGF- $\beta 3$ ) and TNF- $\alpha$ are actively involved in junction restructuring in the seminiferous epithelium, thus facilitating the movement of developing germ cells. These cytokines are secreted by Sertoli and germ cells in a stage-specific manner. For instance, TGF- $\beta 3$ and TNF- $\alpha$ are expressed at their highest in stages VIIVIII tubules (Lui et al. 2003b, Siu et al. 2003), similar to the expression of the AR. Recent studies have unraveled the molecular mechanism by which these cytokines exert their effects to modulate junction dynamics. In fact, TGF- $\beta$ s and TNF- $\alpha$ regulate the junction restructuring via various control mechanisms at the transcriptional, post-transcriptional and post-translational levels.

\section{Transforming growth factor- $\beta$ s}

TGF- $\beta$ s are a group of cytokines that have been extensively studied by both in vitro and in vivo models in regard to their roles in junction restructuring (Lui et al. 2003b, c, Xia \& Cheng 2005, Xia et al. 2006). TGF- $\beta 3$ is a crucial cytokine that modulates the disassembly of the BTB, the apical ES and the AJ by down-regulating the expression of integral membrane proteins such as occludin and N-cadherin (Lui et al. 2001, 2003b, Xia \& Cheng 2005, Xia et al. 2006). It is noted that TGF- $\beta 3$ can exert distinctive effects on junction restructuring by interacting with selective adaptors to evoke different signaling pathways. The interaction of the TGF- $33 /$ T $\beta$ RI complex with both CD2AP and TAB1 adaptors triggers the activation of both p38 and ERK pathways, resulting in the disruption of the BTB and apical ES in the seminiferous epithelium (Lui et al. 2001, 2003b, Xia et al. 2006). However, if the TGF- $\beta 3 / T \beta R I$ complex interacts with CD2AP alone, only the ERK pathway will be activated. Such activation can effectively disrupt the AJs between Sertoli and germ cells, but not the BTB and basal ES (Xia \& Cheng 2005, Lui \& Cheng 2007).

While TGF- $\beta 3$ was found to differentially regulate apical ES and/or BTB junctions, TGF- $\beta 2$ was shown to reduce the junctional adhesion molecule-B (JAM-B) protein level via transcriptional repression in cultured Sertoli cells (Wang \& Lui 2009). In the testis, JAM-B is expressed by Sertoli cells and localized at the apical ES to form interlocks with (JAM-C) for spermatid attachment (Gliki et al. 2004). It was found that TGF- $\beta 2$ exerted its negative regulatory effects on the JAM-B transcription via activation of Smad proteins. Activated Smad proteins effectively displaced $\mathrm{Sp} 1$ proteins from the TGIF motif of JAM-B promoter, resulting in JAM-B repression (Wang \& Lui 2009).

It is apparent that the reduction of the junction protein level within cells, either by suppressing de novo protein synthesis or promoting its protein degradation, is an effective approach to modulating junction restructuring. A recent study has shown that TGF- $\beta 2$ can alter the bioavailability of junction proteins at the cell-cell interface by accelerating protein degradation (Yan et al. 2008a). It has been found that both TGF- $\beta 2$ and testosterone can accelerate the kinetics of internalization of the BTB proteins from the cell surface. However, the fates of internalized proteins triggered by TGF- $\beta 2$ and testosterone are entirely different. TGF- $\beta 2$ accelerates the internalization of integral membrane proteins (such as JAM-A and occludin) via a clathrincoated pit and targets the internalized proteins into late endosomes for degradation, leading to the disassembly of the BTB; whereas testosterone accelerates the internalization of integral membrane proteins and their transcytosis to form new junction fibrils beneath the migrating spermatocyte (Yan et al. 2008a).

\section{Tumor necrosis factor- $\alpha$}

TNF- $\alpha$ is produced by Sertoli and germ cells in the testis and is a crucial cytokine that regulates a wide range of cellular processes in the testis (Mruk \& Cheng 2004). It controls steroidogenesis in Leydig cells and survival of germ cells by interfering signaling transduction of the Fas-ligand system (Pentikainen et al. 2001, Hong et al. 2004). Analysis of adult rats having chronically systemic administration of TNF- $\alpha$ has uncovered the possible role of TNF- $\alpha$ on junction restructuring in the testis (Mealy et al. 1990). It was found that the loss of germ cells from the seminiferous epithelium in this animal model was not due to inflammatory responses. In fact, TNF- $\alpha$ exerted its effect on Sertoli-germ cell interface, resulting in premature germ cell loss from the epithelium (Mealy et al. 1990). To elucidate the mechanism on how TNF- $\alpha$ perturbs cell junctions between Sertoli and germ cells, Li et al. (2006) have established another in vivo model by local administration of recombinant TNF- $\alpha$ into rat testes. It was found that there was a significant increase in FITC diffusion across the BTB in the seminiferous tubules along with the reduction of occludin and ZO-1 protein levels in the testis lysate, which clearly illustrates the disruption of the BTB upon TNF- $\alpha$ treatment ( $\mathrm{Li}$ et al. 2006). Apart from the BTB impairment, TNF- $\alpha$ is capable of causing disorganization of the actin bundles and cisternae of endoplasmic reticulum at the apical ES, leading to the release of premature spermatids (Li et al. 2006; Fig. 2).

Like occludin and ZO-1, coxsackie- and adenovirus receptor-like membrane protein (CLMP) is another TJ protein at the BTB which can be negatively regulated by TNF- $\alpha$. In a recent study, it has been demonstrated that TNF- $\alpha$ can act on the CLMP mRNA transcript and destabilize the transcript by promoting the binding of 

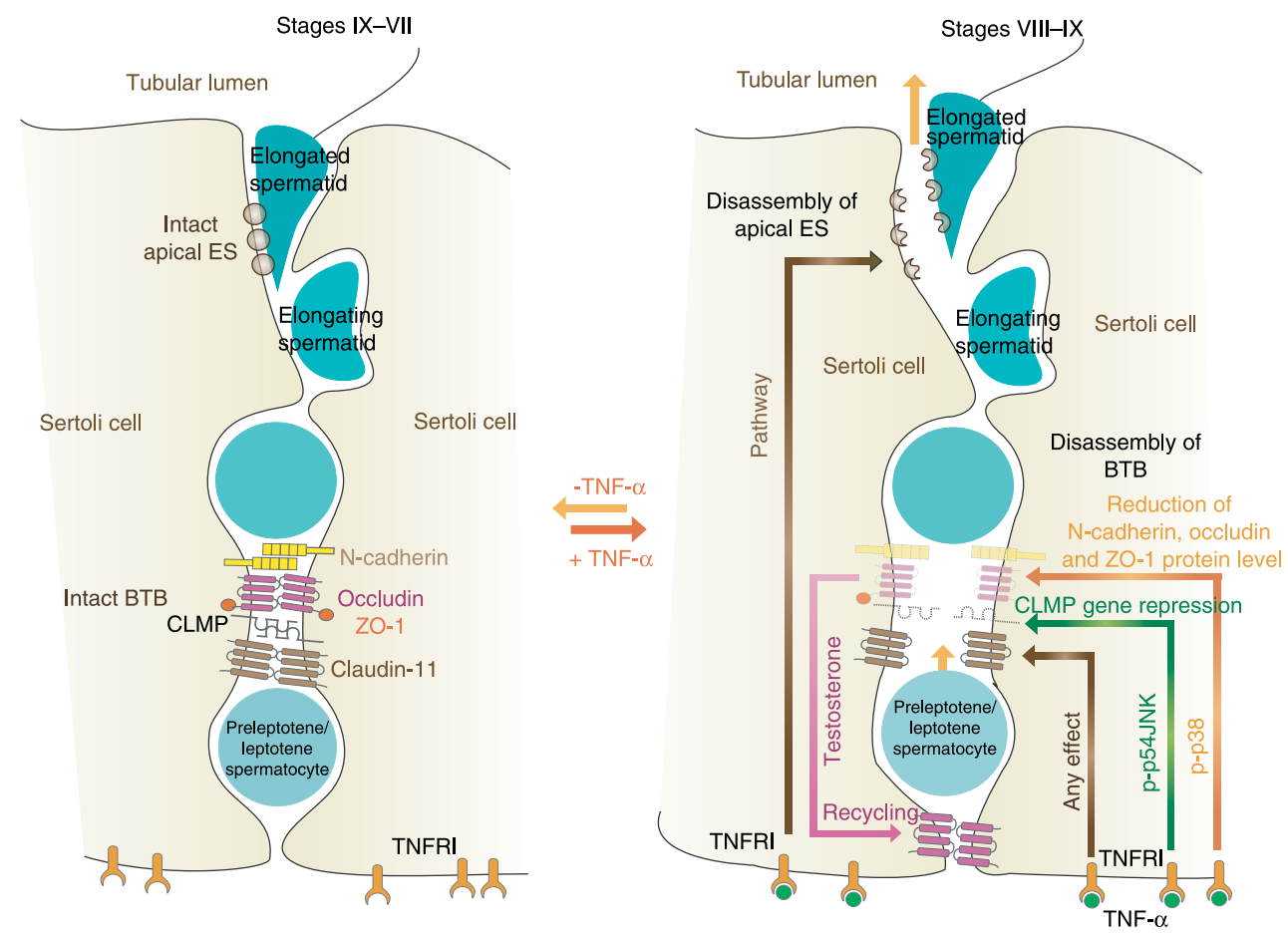

Figure $2 \mathrm{~A}$ schematic drawing illustrates the effect of TNF- $\alpha$ on junction restructuring in the seminiferous epithelium. Intact ES and BTB are maintained in the absence of TNF- $\alpha$. At stage VIII of the epithelial cycle, a surge of TNF- $\alpha$ triggers different MAPK pathways and regulates the opening of the BTB (Li et al. 2006, Sze et al. 2008) as well as the apical ES (Mealy et al. 1990) by controlling the junction protein levels and altering the transcription of junction proteins to allow the migration of preleptotene/leptotene spermatocytes across the BTB and the release of mature spermatids to the tubular lumen. It is also noted that at stage VIII, testosterone enhances transcytosis of occludin in Sertoli cells, possibly from the cell surface at the apical end of the migrating spermatocytes to cell surface at the basal end to reassemble the BTB (Yan et al. 2008a). TNF- $\alpha$, tumor necrosis factor- $\alpha$; TNFRI, tumor necrosis factor receptor I; ZO-1, zonula occludens-1, BTB, blood-testis barrier; ES, ectoplasmic specializations.

an RNA-binding protein, tristetraprolin, at the $3^{\prime} \mathrm{UTR}$ region under the activation of the c-Jun N-terminal kinase (JNK) pathway (Sze et al. 2008). This study illustrates that TNF- $\alpha$ disassembles TJ proteins at the BTB, possibly including regulation at post-transcriptional level by affecting the mRNA stability (Fig. 2).

\section{Bioactive peptides released from proteolysis}

Apart from the above-mentioned regulator, an emergence of significance in relation to the testis is the role of biological peptides generated by the breakdown of adhesion complexes and ECM proteins. The recently identified autocrine axis, coordinating the events of BTB restructuring and spermiation which take place concurrently at the opposite ends of the seminiferous epithelium, is proposed to be mediated by fragments of laminin chains released from the dissociation of spermatid-Sertoli cell adhesion (Yan et al. 2008b).
The disruption of the BTB by TNF- $\alpha$ and other cytokines is also proposed to be mediated by collagen fragments resulting from proteolytic cleavages of the ECM proteins (Siu et al. 2003, Yan et al. 2008a). These laminin and collagen fragments that coordinate events within the testis are in fact functioning as paracrine factors. Sertoli cells produce a variety of matrix metalloproteases and tissue inhibitors of metalloproteases (Siu et al. 2003, Siu \& Cheng 2004). Studies of the proteolysis and proteolytic fragments in the testis deserve greater attention, as the identification of unique coordination pathways in regulating junction restructuring has the potential for the development of a non-hormonal male contraceptive.

\section{Concluding remarks}

Undoubtedly, these biomolecules are important regulators in many aspects of spermatogenesis, especially junction restructuring, and in most of cases, detailed 
mechanisms on how these molecules exert their functions have been examined. However, there are still ample scattered data in the literature showing that other biomolecules such as hepatocyte growth factor and nitric oxide play a role in junction restructuring in vitro (Lee \& Cheng 2003, Catizone et al. 2008), yet their effects have not been fully examined in animal models. Needless to say, much of the research efforts should be allocated to uncovering the underlying mechanisms of each individual regulator. Even so, the challenge we have to confront is how to delineate the possible coordination between these biomolecules in modulating junction restructuring in the testis. The use of advanced cell biology techniques, such as overexpression and gene knock-down (RNAi) studies in primary cell cultures and the application of bioinformatics should, hopefully, be helpful in expanding this area of research, and even in assuring that a systematic overview of spermatogenesis under the control of various regulators can be simulated in the near future.

\section{Declaration of interest}

The authors declare that there is no conflict of interest that could be perceived as prejudicing the impartiality of the research reported.

\section{Funding}

This work was supported by Hong Kong Research Grants Council (HKU7715/07M to W-Y L and HKU7693/07M to W M L).

\section{References}

Beardsley A \& O'Donnell L 2003 Characterization of normal spermiation and spermiation failure induced by hormone suppression in adult rats. Biology of Reproduction 68 1299-1307.

Beardsley A, Robertson DM \& O'Donnell L 2006 A complex containing alpha6betal-integrin and phosphorylated focal adhesion kinase between Sertoli cells and elongated spermatids during spermatid release from the seminiferous epithelium. Journal of Endocrinology 190 759-770.

Bremner WJ, Millar MR, Sharpe RM \& Saunders PT 1994 Immunohistochemical localization of androgen receptors in the rat testis: evidence for stage-dependent expression and regulation by androgens. Endocrinology 135 1227-1234.

Catizone A, Ricci G \& Galdieri M 2008 Hepatocyte growth factor modulates Sertoli-Sertoli tight junction dynamics. Journal of Cellular Physiology 216 253-260.

Chang C, Chen YT, Yeh SD, Xu Q, Wang RS, Guillou F, Lardy H \& Yeh S 2004 Infertility with defective spermatogenesis and hypotestosteronemia in male mice lacking the androgen receptor in Sertoli cells. PNAS 101 6876-6881.

Cheng CY \& Mruk DD 2002 Cell junction dynamics in the testis: Sertoli-germ cell interactions and male contraceptive development. Physiological Reviews 82 825-874.

Chung NP \& Cheng CY 2001 Is cadmium chloride-induced interSertoli tight junction permeability barrier disruption a suitable in vitro model to study the events of junction disassembly during spermatogenesis in the rat testis? Endocrinology 142 1878-1888.
Denolet E, De Gendt K, Allemeersch J, Engelen K, Marchal K, Van Hummelen P, Tan KA, Sharpe RM, Saunders PT, Swinnen JV et al. 2006 The effect of a Sertoli cell-selective knockout of the androgen receptor on testicular gene expression in prepubertal mice. Molecular Endocrinology 20 321-334.

D'Souza R, Pathak S, Upadhyay R, Gaonkar R, D'Souza S, Sonawane S, Gill-Sharma M \& Balasinor NH 2009 Disruption of tubulobulbar complex by high intratesticular estrogens leading to failed spermiation. Endocrinology 150 1861-1869.

De Gendt K, Swinnen JV, Saunders PT, Schoonjans L, Dewerchin M, Devos A, Tan K, Atanassova N, Claessens F, Lecureuil C et al. 2004 A Sertoli cell-selective knockout of the androgen receptor causes spermatogenic arrest in meiosis. PNAS 101 1327-1332.

Gliki G, Ebnet K, Aurrand-Lions M, Imhof BA \& Adams RH 2004 Spermatid differentiation requires the assembly of a cell polarity complex downstream of junctional adhesion molecule-C. Nature 431 320-324.

Gow A, Southwood CM, Li JS, Pariali M, Riordan GP, Brodie SE, Danias J, Bronstein JM, Kachar B \& Lazzarini RA 1999 CNS myelin and Sertoli cell tight junction strands are absent in Osp/claudin-11 null mice. Cell 99 649-659.

Grover A, Sairam MR, Smith CE \& Hermo L 2004 Structural and functional modifications of Sertoli cells in the testis of adult follicle-stimulating hormone receptor knockout mice. Biology of Reproduction 71 117-129.

Hellani A, Ji J, Mauduit C, Deschildre C, Tabone E \& Benahmed M 2000 Developmental and hormonal regulation of the expression of oligodendrocyte-specific protein/claudin-11 in mouse testis. Endocrinology 141 3012-3019.

Holdcraft RW \& Braun RE 2004 Androgen receptor function is required in Sertoli cells for the terminal differentiation of haploid spermatids. Development 131 459-467.

Hong CY, Park JH, Ahn RS, Im SY, Choi HS, Soh J, Mellon SH \& Lee K 2004 Molecular mechanism of suppression of testicular steroidogenesis by proinflammatory cytokine tumor necrosis factor alpha. Molecular and Cellular Biology 24 2593-2604.

Huang HF, Marshall GR, Rosenberg R \& Nieschlag E 1987 Restoration of spermatogenesis by high levels of testosterone in hypophysectomized rats after long-term regression. Acta Endocrinologica 116 433-444.

Kaitu'u-Lino TJ, Sluka P, Foo CF \& Stanton PG 2007 Claudin-11 expression and localization is regulated by androgens in rat Sertoli cells in vitro. Reproduction 133 1169-1179.

Kliesch S, Penttila TL, Gromoll J, Saunders PT, Nieschlag E \& Parvinen M 1992 FSH receptor mRNA is expressed stage-dependently during rat spermatogenesis. Molecular and Cellular Endocrinology 84 R45-R49.

Krishnamurthy H, Danilovich N, Morales CR \& Sairam MR 2000 Qualitative and quantitative decline in spermatogenesis of the follicle-stimulating hormone receptor knockout (FORKO) mouse. Biology of Reproduction 62 1146-1159.

Lee NP \& Cheng CY 2003 Regulation of Sertoli cell tight junction dynamics in the rat testis via the nitric oxide synthase/soluble guanylate cyclase $/ 3^{\prime}, 5^{\prime}$-cyclic guanosine monophosphate/protein kinase G signaling pathway: an in vitro study. Endocrinology 144 3114-3129.

Li MW, Xia W, Mruk DD, Wang CQ, Yan HH, Siu MK, Lui WY, Lee WM \& Cheng CY 2006 Tumor necrosis factor alpha reversibly disrupts the blood-testis barrier and impairs Sertoli-germ cell adhesion in the seminiferous epithelium of adult rat testes. Journal of Endocrinology 190 313-329.

Lui WY \& Cheng CY 2007 Regulation of cell junction dynamics by cytokines in the testis: a molecular and biochemical perspective. Cytokine and Growth Factor Reviews 18 299-311.

Lui WY \& Lee WM 2006 Regulation of junction dynamics in the testis-transcriptional and post-translational regulations of cell junction proteins. Molecular and Cellular Endocrinology 250 25-35. 
Lui WY, Lee WM \& Cheng CY 2001 Transforming growth factor-beta3 perturbs the inter-Sertoli tight junction permeability barrier in vitro possibly mediated via its effects on occludin, zonula occludens-1, and claudin-11. Endocrinology 142 1865-1877.

Lui WY, Lee WM \& Cheng CY $2003 a$ TGF-betas: their role in testicular function and Sertoli cell tight junction dynamics. International Journal of Andrology 26 147-160.

Lui WY, Lee WM \& Cheng CY $2003 b$ Transforming growth factor-beta3 regulates the dynamics of Sertoli cell tight junctions via the p38 mitogen-activated protein kinase pathway. Biology of Reproduction 68 $1597-1612$.

Lui WY, Wong CH, Mruk DD \& Cheng CY 2003c TGF-beta3 regulates the blood-testis barrier dynamics via the p38 mitogen activated protein (MAP) kinase pathway: an in vivo study. Endocrinology 144 $1139-1142$

McLachlan RI, Wreford NG, Meachem SJ, De Kretser DM \& Robertson DM 1994 Effects of testosterone on spermatogenic cell populations in the adult rat. Biology of Reproduction 51 945-955.

McLachlan RI, O’Donnell L, Meachem SJ, Stanton PG, de Kretser DM, Pratis K \& Robertson DM 2002 Identification of specific sites of hormonal regulation in spermatogenesis in rats, monkeys, and man. Recent Progress in Hormone Research 57 149-179.

Mealy K, Robinson B, Millette CF, Majzoub J \& Wilmore DW 1990 The testicular effects of tumor necrosis factor. Annals of Surgery 211 $470-475$.

Meng J, Holdcraft RW, Shima JE, Griswold MD \& Braun RE 2005 Androgens regulate the permeability of the blood-testis barrier. PNAS 102 16696-16700.

Mirza M, Petersen C, Nordqvist K \& Sollerbrant K 2007 Coxsackievirus and adenovirus receptor is up-regulated in migratory germ cells during passage of the blood-testis barrier. Endocrinology 148 5459-5469.

Mruk DD \& Cheng CY 2004 Sertoli-Sertoli and Sertoli-germ cell interactions and their significance in germ cell movement in the seminiferous epithelium during spermatogenesis. Endocrine Reviews $25747-806$.

Muffly KE, Nazian SJ \& Cameron DF 1994 Effects of follicle-stimulating hormone on the junction-related Sertoli cell cytoskeleton and daily sperm production in testosterone-treated hypophysectomized rats. Biology of Reproduction 51 158-166.

O'Donnell L, McLachlan RI, Wreford NG \& Robertson DM 1994 Testosterone promotes the conversion of round spermatids between stages VII and VIII of the rat spermatogenic cycle. Endocrinology 135 2608-2614.

O’Donnell L, McLachlan RI, Wreford NG, de Kretser DM \& Robertson DM 1996 Testosterone withdrawal promotes stage-specific detachment of round spermatids from the rat seminiferous epithelium. Biology of Reproduction $\mathbf{5 5}$ 895-901.

O'Donnell L, Meachem SJ, Stanton PG \& McLachlan RI 2005 The endocrine regulation of spermatogenesis. In The Physiology of Reproduction, pp 1017-1070. Eds E Knobil \& JD Kneill. San Diego, CA, USA: Elsevier.

Pentikainen V, Erkkila K, Suomalainen L, Otala M, Pentikainen MO, Parvinen M \& Dunkel L 2001 TNFalpha down-regulates the Fas ligand and inhibits germ cell apoptosis in the human testis. Journal of Clinical Endocrinology and Metabolism 86 $4480-4488$.

Rahman F \& Christian HC 2007 Non-classical actions of testosterone: an update. Trends in Endocrinology and Metabolism 18 371-378.

Saito K, O’Donnell L, McLachlan RI \& Robertson DM 2000 Spermiation failure is a major contributor to early spermatogenic suppression caused by hormone withdrawal in adult rats. Endocrinology 141 2779-2785.

Shan LX, Bardin CW \& Hardy MP 1997 Immunohistochemical analysis of androgen effects on androgen receptor expression in developing Leydig and Sertoli cells. Endocrinology 138 1259-1266.
Siu MK \& Cheng CY 2004 Dynamic cross-talk between cells and the extracellular matrix in the testis. BioEssays 26 978-992.

Siu MK, Lee WM \& Cheng CY 2003 The interplay of collagen IV, tumor necrosis factor-alpha, gelatinase B (matrix metalloprotease-9), and tissue inhibitor of metalloproteases-1 in the basal lamina regulates Sertoli cell-tight junction dynamics in the rat testis. Endocrinology 144 371-387.

Sluka P, O'Donnell L, Bartles JR \& Stanton PG 2006 FSH regulates the formation of adherens junctions and ectoplasmic specializations between rat Sertoli cells in vitro and in vivo. Journal of Endocrinology 189 381-395.

Sofikitis N, Giotitsas N, Tsounapi P, Baltogiannis D, Giannakis D \& Pardalidis N 2008 Hormonal regulation of spermatogenesis and spermiogenesis. Journal of Steroid Biochemistry and Molecular Biology 109 323-330.

Sun YT, Irby DC, Robertson DM \& de Kretser DM 1989 The effects of exogenously administered testosterone on spermatogenesis in intact and hypophysectomized rats. Endocrinology 125 $1000-1010$.

Sun YT, Wreford NG, Robertson DM \& de Kretser DM 1990 Quantitative cytological studies of spermatogenesis in intact and hypophysectomized rats: identification of androgen-dependent stages. Endocrinology 127 1215-1223.

Sze KL, Lui WY \& Lee WM 2008 Post-transcriptional regulation of CLMP mRNA is controlled by tristetraprolin in response to TNFalpha via c-Jun N-terminal kinase signalling. Biochemical Journal 410 575-583.

Tarulli GA, Stanton PG, Lerchl A \& Meachem SJ 2006 Adult Sertoli cells are not terminally differentiated in the Djungarian hamster: effect of FSH on proliferation and junction protein organization. Biology of Reproduction 74 798-806.

Tarulli GA, Meachem SJ, Schlatt S \& Stanton PG 2008 Regulation of testicular tight junctions by gonadotrophins in the adult Djungarian hamster in vivo. Reproduction 135 867-877.

Wang Y \& Lui WY 2009 Opposite effects of interleukin- $1 \alpha$ and transforming growth factor- $\beta 2$ induce stage-specific regulation of junctional adhesion molecule-B gene in Sertoli cells. Endocrinology 150 2404-2412.

Wilson EM \& French FS 1976 Binding properties of androgen receptors. Evidence for identical receptors in rat testis, epididymis, and prostate. Journal of Biological Chemistry 251 $5620-5629$.

Wong CH, Xia W, Lee NP, Mruk DD, Lee WM \& Cheng CY 2005 Regulation of ectoplasmic specialization dynamics in the seminiferous epithelium by focal adhesion-associated proteins in testosterone-suppressed rat testes. Endocrinology 146 1192-1204.

Wong EW, Mruk DD \& Cheng CY 2008 Biology and regulation of ectoplasmic specialization, an atypical adherens junction type, in the testis. Biochimica et Biophysica Acta 1778 692-708.

Xia W \& Cheng CY 2005 TGF-beta3 regulates anchoring junction dynamics in the seminiferous epithelium of the rat testis via the Ras/ERK signaling pathway: an in vivo study. Developmental Biology 280 321-343.

Xia W, Mruk DD, Lee WM \& Cheng CY 2006 Differential interactions between transforming growth factor-beta3/TbetaR1, TAB1, and CD2AP disrupt blood-testis barrier and Sertoli-germ cell adhesion. Journal of Biological Chemistry 281 16799-16813.

Yan HH \& Cheng CY 2006 Laminin alpha 3 forms a complex with beta3 and gamma3 chains that serves as the ligand for alpha6betal-integrin at the apical ectoplasmic specialization in adult rat testes. Journal of Biological Chemistry 281 17286-17303.

Yan HH, Mruk DD, Lee WM \& Cheng CY 2008a Blood-testis barrier dynamics are regulated by testosterone and cytokines via their differential effects on the kinetics of protein endocytosis and recycling in Sertoli cells. FASEB Journal 22 1945-1959. 
Yan HH, Mruk DD, Wong EW, Lee WM \& Cheng CY $2008 b$ An autocrine axis in the testis that coordinates spermiation and blood-testis barrier restructuring during spermatogenesis. PNAS $1058950-8955$.

Yeh S, Tsai MY, Xu Q, Mu XM, Lardy H, Huang KE, Lin H, Yeh SD, Altuwaijri S, Zhou X et al. 2002 Generation and characterization of androgen receptor knockout (ARKO) mice: an in vivo model for the study of androgen functions in selective tissues. PNAS $\mathbf{9 9}$ 13498-13503.

Zhang J, Mruk DD \& Cheng CY $2005 a$ Myotubularin phosphoinositide phosphatases, protein phosphatases, and kinases: their roles in junction dynamics and spermatogenesis. Journal of Cellular Physiology 204 470-483.
Zhang J, Wong CH, Xia W, Mruk DD, Lee NP, Lee WM \& Cheng CY $2005 b$ Regulation of Sertoli-germ cell adherens junction dynamics via changes in protein-protein interactions of the $\mathrm{N}$-cadherin-beta-catenin protein complex which are possibly mediated by c-Src and myotubularin-related protein 2: an in vivo study using an androgen suppression model. Endocrinology 146 $1268-1284$

Received in final form 14 January 2009

Accepted 9 March 2009

Made available online as an Accepted Preprint 9 March 2009 